\title{
Refractory hypercalcemia owing to vitamin A toxicity in a 4-year-old boy
}

\author{
Melissa Lorenzo MD, Maxime Nadeau MD, Jennifer Harrington MD PhD, Peter J. Gill MD DPhil
}

Cite as: CMAJ 2020 June 22;192:E671-5. doi: 10.1503/cmaj.191568

A 4-year-old, previously healthy boy presented to the emergency department with a 2-day history of polydipsia, fatigue, irritability, cheilitis and a refusal to bear weight. One month previously, he had had an episode of similar symptoms, which had resolved. His vital signs, height $(102.4 \mathrm{~cm})$, weight $(16.7 \mathrm{~kg})$ and body mass index $\left(15.9 \mathrm{~kg} / \mathrm{m}^{2}\right)$ were normal (Box 1$)$. He appeared pale, with significant cheilitis, xerotic skin, diffuse alopecia and periorbital and pedal edema (Figure 1). Initial investigations were significant for severe hypercalcemia, hyponatremia, hypokalemia, mildly elevated creatinine, elevated C-reactive protein, leukocytosis and normocytic anemia (Box 1). Abdominal ultrasound showed bilateral pelviectasis and medullary nephrocalcinosis. We admitted the patient to hospital and started hyperhydration with intravenous (IV) fluids.

Initial investigations showed an appropriately low parathyroid hormone and 1,25-dihydroxyvitamin $\mathrm{D}\left(1,25(\mathrm{OH})_{2} \mathrm{D}\right)$, with a normal thyroid-stimulating hormone level. We also ordered tests for parathyroid hormone-related peptide, vitamin A and 25-hydroxyvitamin D (25[OH]D) levels. Skeletal radiographs identified diffuse osteopenia, and periosteal reactions along the ribs, both radii and clavicles.

While in hospital, our patient developed persistent and worsening bicytopenia, with low platelets and hemoglobin necessitating a blood transfusion. A workup for malignant disease, including bone marrow aspirate with flow cytometry, as well as urine vanillylmandelic acid and homovanillic acid, were negative. Despite being afebrile with normal vital signs and negative blood cultures, the patient had persistently elevated inflammatory markers, which gradually reduced without treatment.

Magnetic resonance imaging of the brain, spine and chest identified elevated optic discs and no other structural abnormality, consistent with pseudotumour cerebri. An ophthalmologist verified grade 3 papilledema, for which the patient was started on acetazolamide. He also had elevated liver enzymes, a prolonged international normalized ratio and hypoalbuminemia. A liver ultrasound showed hepatomegaly, and abnormal sheer wave elastography was suggestive of fibrosis. Serum and urine toxicology screen, and viral (cytomegalovirus, Epstein-Barr virus and hepatitis $A, B$ and $C$ ) and autoimmune hepatitis workup were negative.

After the patient had spent 2 weeks in hospital, we received the results of his outstanding investigations (Box 1). His parathyroid hormone-related peptide and total $25(\mathrm{OH}) \mathrm{D}$ levels were normal, but

\section{KEY POINTS}

- Vitamin A toxicity should be considered in the differential diagnosis for severe hypercalcemia.

- Symptoms of vitamin A toxicity are nonspecific, and may include nausea, fatigue, lethargy, anorexia, pruritis, headache and bone pain. Clinical features may include nephrocalcinosis, cheilitis, alopecia, pseudotumour cerebri and liver toxicity.

- Children can develop vitamin A toxicity at lower total doses than those required to cause toxicity in adults.

- Vitamin A toxicity can occur at what people perceive to be "safe doses" of vitamin A from dietary sources and supplementation.

- Diet and supplement history should be obtained for all patients, especially those whose diagnosis remains elusive.

the vitamin A level was significantly elevated at 4.1 (reference 1.01.6) $\mu \mathrm{mol} / \mathrm{L}$. Because of his elevated vitamin A level, we carefully reviewed his diet and supplement intake. He was on a predominantly plant-based diet, and we estimated his vitamin A intake to be between $1528 \mu \mathrm{g}$ and $3304 \mu \mathrm{g}$ of retinol activity equivalents (RAE) per day, or 31087-63507 international units (IU) per day (recommended intake for children at the age of our patient is $400 \mu \mathrm{g} / \mathrm{d}$ RAE). We referred to the US Department of Agriculture to provide the levels of vitamin A in the foods (https://fdc.nal.usda. gov/) and the conversion of factors for RAE and IU from the US National Institutes of Health (Box 2). The patient's main sources of vitamin A included 1-2 cups of kale, 2-3 cups of green vegetables, $2-3$ cups of fruit and 4 oz of meat per day (nonliver), plus a multivitamin containing vitamin A as $\beta$-carotene ( $28 \mu \mathrm{g}$ RAE). He had previously been taking cod liver oil supplements ( $276 \mu \mathrm{g} /$ day RAE) for more than 1 year, but had stopped many months previously.

We managed the patient's hypercalcemia with IV hyperhydration, multiple doses of subcutaneous calcitonin and IV bisphosphonates and a low vitamin A diet (Figure 2). We discharged him home with a normal ionized calcium, and 1 month after discharge, his hypercalcemia and bicytopenia had resolved. His papilledema improved and he was tapered off acetazolamide. His liver markers remain mildly elevated, with ongoing evidence of fibrosis on liver ultrasound. Five months after discharge, the patient sustained a femoral fracture from a fall from standing height. 
Box 1: Select laboratory findings on patient's presentation to hospital

\begin{tabular}{|c|c|c|}
\hline Investigation & Result & Reference range \\
\hline Hemoglobin & $89 \mathrm{~g} / \mathrm{L}$ (low) & $102-127 \mathrm{~g} / \mathrm{L}$ \\
\hline Mean corpuscular volume & $81.3 \mathrm{fL}$ (normal) & $71.3-84 \mathrm{fL}$ \\
\hline Platelets & $\begin{array}{l}265 \times 10^{9} / \mathrm{L} \\
\text { (normal) }\end{array}$ & $202-403 \times 10^{9} / \mathrm{L}$ \\
\hline Leukocytes & $\begin{array}{l}16.6 \times 10^{9} / \mathrm{L} \\
\text { (high) }\end{array}$ & $5.1-13.4 \times 10^{9} / \mathrm{L}$ \\
\hline Sodium & $\begin{array}{l}133 \mathrm{mmol} / \mathrm{L} \\
\quad \text { (low) }\end{array}$ & $135-143 \mathrm{mmol} / \mathrm{L}$ \\
\hline Potassium & 3.6 mmol/L (low) & $3.7-5 \mathrm{mmol} / \mathrm{L}$ \\
\hline Phosphate & $\begin{array}{c}1.67 \mathrm{mmol} / \mathrm{L} \\
\text { (normal) }\end{array}$ & $1.41-2.17 \mathrm{mmol} / \mathrm{L}$ \\
\hline Total calcium & $\begin{array}{l}3.85 \mathrm{mmol} / \mathrm{L} \\
\text { (high) }\end{array}$ & $2.22-2.54 \mathrm{mmol} / \mathrm{L}$ \\
\hline Ionized calcium & $\begin{array}{l}2.02 \mathrm{mmol} / \mathrm{L} \\
\text { (high) }\end{array}$ & $1.22-1.37 \mathrm{mmol} / \mathrm{L}$ \\
\hline Creatinine & 46 بmol/L (high) & $18-38 \mu \mathrm{mol} / \mathrm{L}$ \\
\hline C-reactive protein & 69.6 mg/L (high) & $0.1-1.0 \mathrm{mg} / \mathrm{L}$ \\
\hline $\begin{array}{l}\text { Aspartate } \\
\text { aminotransferase }\end{array}$ & 128 U/L (high) & $<52 \mathrm{U} / \mathrm{L}$ \\
\hline Alanine aminotransferase & 65 U/L (high) & $<44 \mathrm{U} / \mathrm{L}$ \\
\hline Albumin & $26 \mathrm{~g} / \mathrm{L}$ (low) & $35-47 \mathrm{~g} / \mathrm{L}$ \\
\hline $\begin{array}{l}\text { International normalized } \\
\text { ratio }\end{array}$ & 1.4 (high) & $0.8-1.2$ \\
\hline $\begin{array}{l}\text { Thyroid-stimulating } \\
\text { hormone }\end{array}$ & $\begin{array}{c}1.38 \mathrm{mLU} / \mathrm{L} \\
\text { (normal) }\end{array}$ & $0.73-4.09 \mathrm{mLU} / \mathrm{L}$ \\
\hline Parathyroid hormone & $<5 \mathrm{ng} / \mathrm{L}$ (low) & $12-78 \mathrm{ng} / \mathrm{L}$ \\
\hline $\begin{array}{l}\text { Parathyroid hormone- } \\
\text { related peptide }\end{array}$ & $\begin{array}{l}14 \mathrm{pg} / \mathrm{mL} \\
\text { (normal) }\end{array}$ & $14-27 \mathrm{pg} / \mathrm{mL}$ \\
\hline $25(\mathrm{OH}) \mathrm{D}$ & $\begin{array}{l}182 \mathrm{nmol} / \mathrm{L} \\
\text { (normal) }\end{array}$ & $70-250 \mathrm{nmol} / \mathrm{L}$ \\
\hline $1,25(\mathrm{OH})_{2} \mathrm{D}$ & 39 pmol/L (low) & 48-190 pmol/L \\
\hline Vitamin $A^{*}$ & $\begin{array}{c}4.1 \mu \mathrm{mol} / \mathrm{L} \\
\text { (high) }\end{array}$ & $1-1.6 \mu \mathrm{mol} / \mathrm{L}$ \\
\hline
\end{tabular}

Note: $1,25(\mathrm{OH})_{2} \mathrm{D}=1,25$-dihydroxyvitamin $\mathrm{D}, 25(\mathrm{OH}) \mathrm{D}=25$-hydroxyvitamin $\mathrm{D}$.

*Vitamin A level was determined by measuring total retinol by high-performance liquid chromatography with ultraviolet detection.

\section{Discussion}

We present a case of a 4-year-old boy with hypercalcemia and classic cutaneous features of vitamin A toxicity, including dry skin, cheilitis and alopecia. ${ }^{1}$ He also had commonly reported symptoms of vitamin A toxicity (i.e., fatigue, anorexia, pruritis, headache and bone pain) and clinical features (i.e., nephrocalcinosis, pseudotumour cerebri and liver toxicity). ${ }^{1}$ He had a low level of parathyroid hormone, low $1,25(\mathrm{OH})_{2} \mathrm{D}$, normal $25(\mathrm{OH}) \mathrm{D}$, and normal parathyroid hormone-related peptide, which helped to narrow the differential diagnosis for hypercalcemia (Figure 3). Ultimately, his vitamin A level was 2.5 times greater than the normal range, which was likely caused by high vitamin A intake.
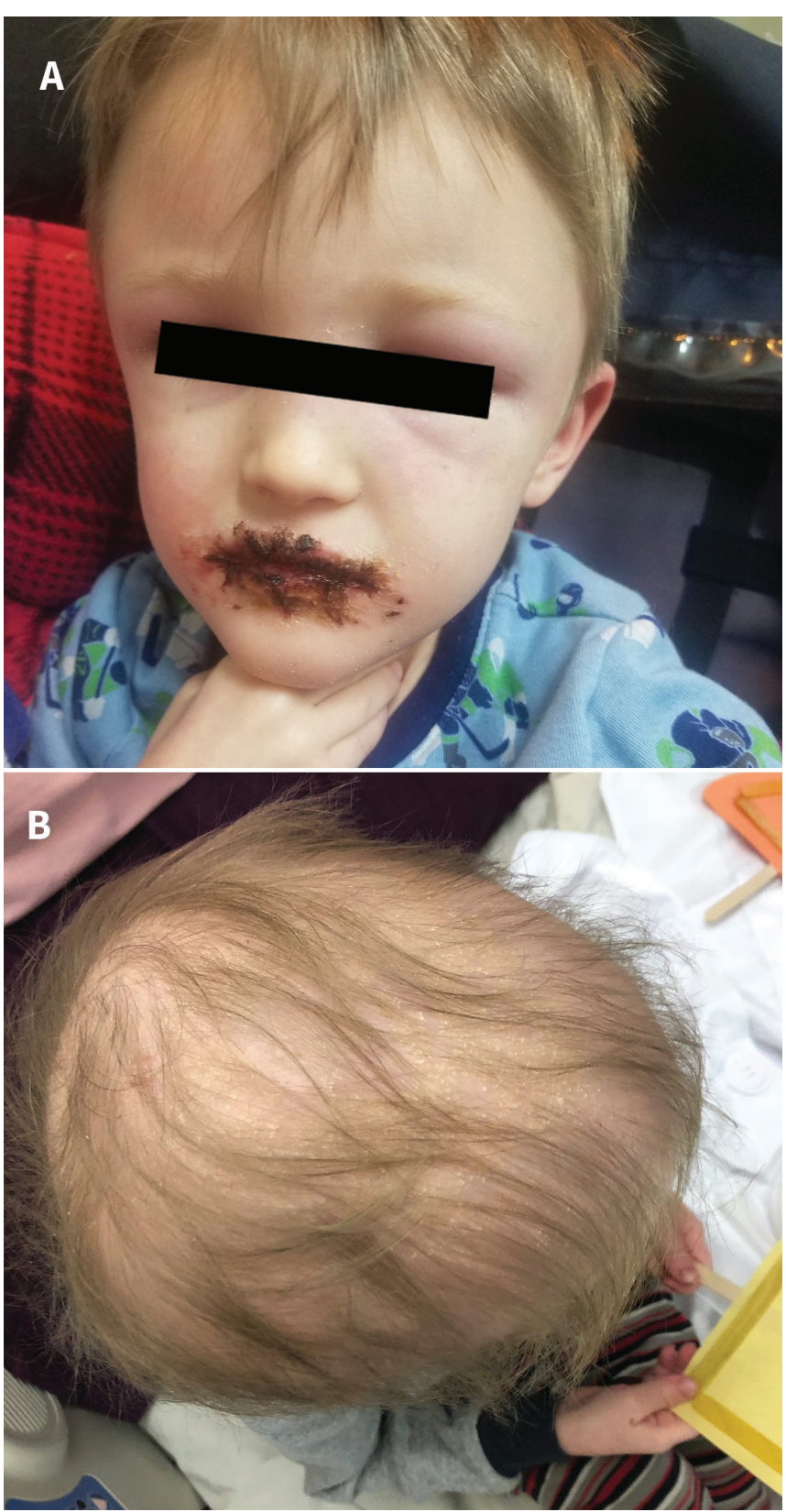

Figure 1: A 4-year-old boy at initial presentation, showing (A) cheilitis and periorbital edema and (B) dry skin and diffuse alopecia. Symptoms of vitamin A toxicity are nonspecific, and may include nausea, fatigue, lethargy, anorexia, pruritis, headache and bone pain. Other clinical features may include nephrocalcinosis, pseudotumour cerebri and liver toxicity.

Vitamin A can be consumed either as preformed vitamin A, in the form of retinol found in animal sources (e.g., meat, liver, liver oils), some multivitamins and fortified foods (e.g., milk, butter, cereals), or as provitamin $A$ ( $\alpha$ - or $\beta$-carotene), found in fruits and vegetables (e.g., kale) and some multivitamins ${ }^{3}$ (Box 2). Vitamin A quantities are measured using RAE, with 1 RAE equal to $1 \mu \mathrm{g}$ retinol, $12 \mu \mathrm{g} \beta$-carotene, or $24 \mu \mathrm{g} \alpha$-carotene. Traditionally, IU were used to measure vitamin $\mathrm{A}$, with $1 \mathrm{IU}$ equal to $0.3 \mu \mathrm{g}$ retinol. It is thought that toxicity cannot be reached with provitamin A foods, as the efficiency of intestinal absorption falls as intake increases and conversion of carotenoids to retinol is regulated. ${ }^{4}$ No pediatric 
Box 2: Common food sources of vitamin A described in units of vitamin A per serving*

\begin{tabular}{|c|c|c|}
\hline \multirow[b]{2}{*}{ Food } & \multicolumn{2}{|c|}{ Vitamin A per serving } \\
\hline & IU & $\mu g$ RAE \\
\hline Raw mango, 1 & 2240 & 112 \\
\hline Raw red pepper, 0.5 cup & 2332 & 117 \\
\hline Raw cantaloupe, 0.5 cup & 2706 & 135 \\
\hline Fortified cereal, 1 cup & 500 & 149 \\
\hline Cooked kale, 0.5 cup & 8854 & 443 \\
\hline Raw carrots, 0.5 cup & 9189 & 459 \\
\hline Boiled spinach, 0.5 cup & 11458 & 573 \\
\hline Sweet potato in skin, 1 & 28058 & 1403 \\
\hline Beef liver, 3 ounces & 22175 & 6582 \\
\hline \multicolumn{3}{|c|}{ 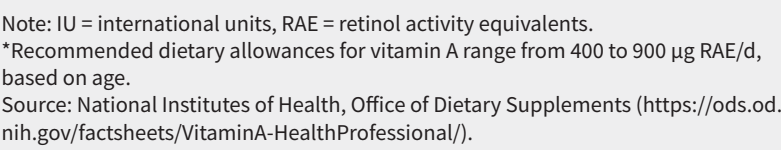 } \\
\hline
\end{tabular}

cases of toxicity have been associated with provitamin A, whereas toxicity from preformed vitamin $\mathrm{A}$ has been reported with acute ingestions exceeding $200000 \mathrm{IU} /$ day over the course of days, ${ }^{5}$ and chronic ingestions of $1500 \mathrm{IU} / \mathrm{kg} /$ day over months to years. ${ }^{3,6}$

Our patient was ingesting 1850-3780 IU/kg/day of predominantly provitamin A for years. While children can develop toxicity at lower total doses of preformed vitamin $\mathrm{A}$ than those required to cause toxicity in adults, our case is somewhat unusual in that the patient was consuming large quantities of provitamin A from fruits and vegetables, notably kale., ${ }^{3,6,7}$ One explanation is that intake of large quantities of provitamin A and preformed vitamin A from cod liver supplements together may have caused toxicity, as the effect of high levels of preformed vitamin $A$ on the metabolism of provitamin A may be synergistic. ${ }^{4}$

Dietary recall is fraught with difficulty, especially with children. Even in optimal circumstances, parents may be uncertain about the dose or duration of supplementation, or inadvertently overlook other supplements.

Vitamin A storage and metabolism is complex. The liver stores $80 \%$ of the body's vitamin A and is susceptible to toxic doses; $; 3$

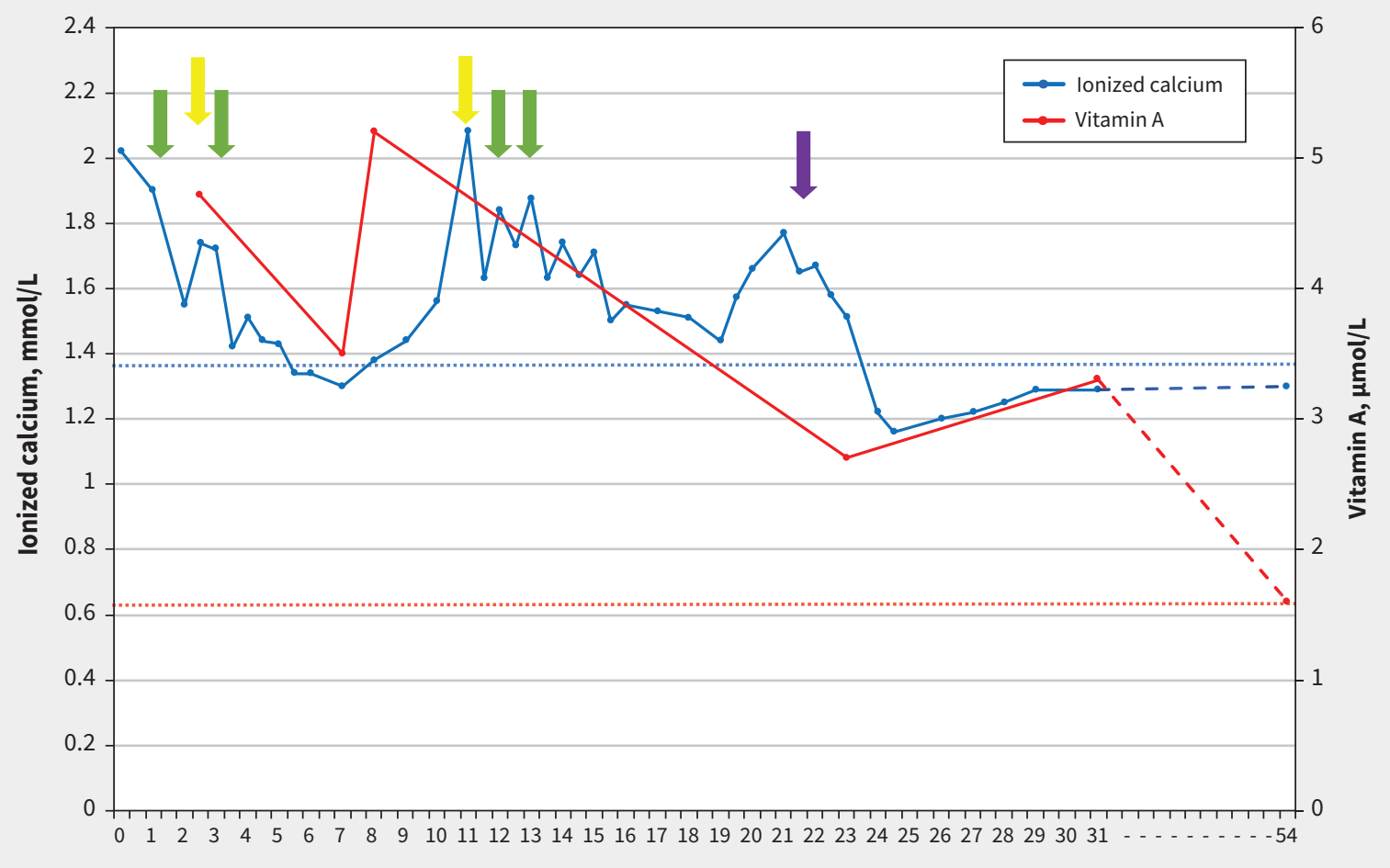

Days from presentation

Figure 2: Trend in patient's ionized calcium $(\mathrm{mmol} / \mathrm{L})$ and vitamin A ( $\mu \mathrm{mol} / \mathrm{L})$ levels over time from date of initial presentation to hospital (days), with treatment for hypercalcemia with calcitonin, pamidronate and zoledronate, indicated by the green, yellow and purple arrows, respectively. The dotted lines along the ionized calcium and vitamin A levels indicate levels from time of discharge (at $31 \mathrm{~d}$ ) to first follow-up ( $54 \mathrm{~d}$ ). The horizontal blue line indicates the upper limit of normal for ionized calcium, and the horizontal red line indicates the upper limit of normal for vitamin A. 


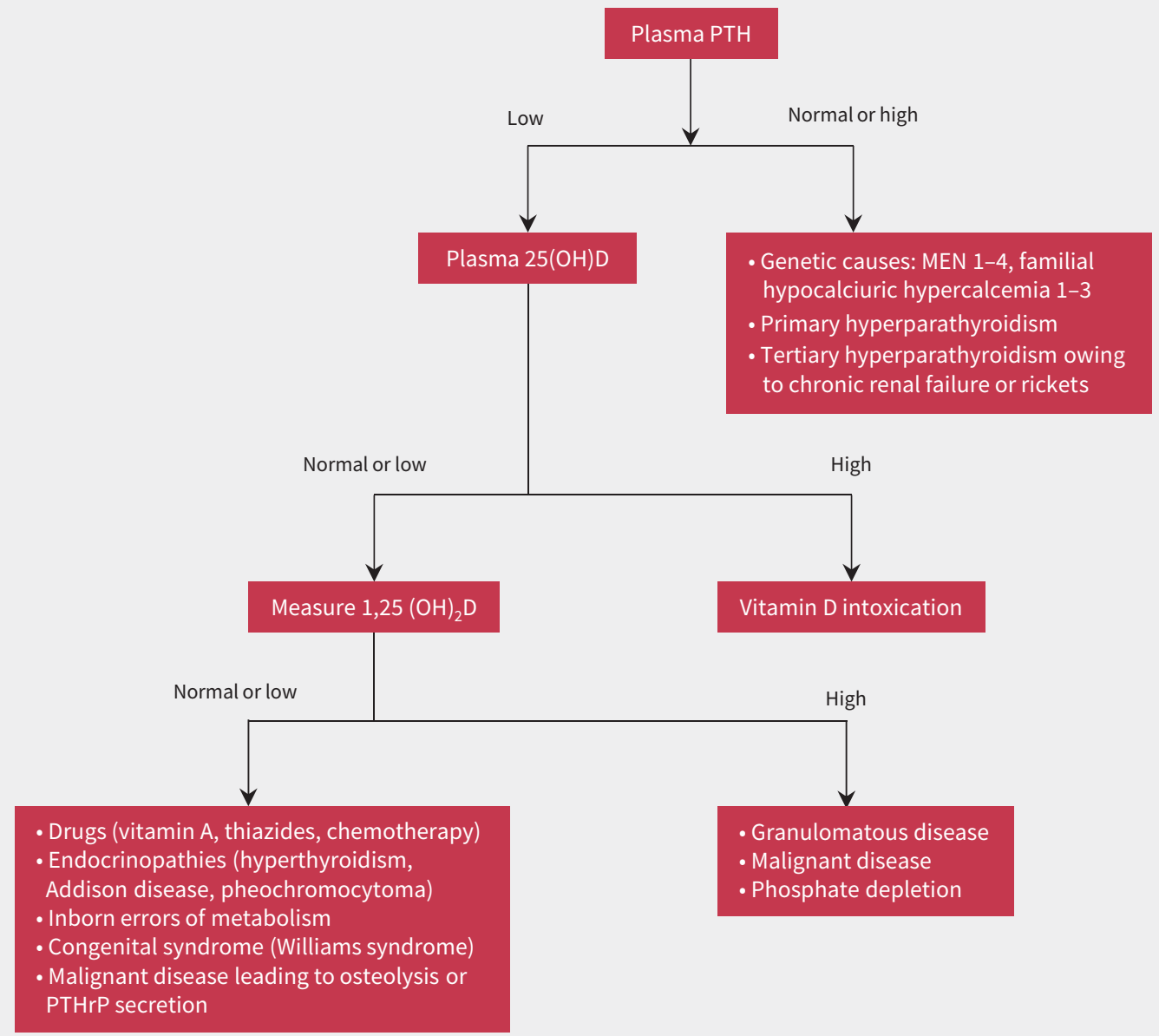

Figure 3: Approach to hypercalcemia. Note: $\mathrm{MEN}=$ multiple endocrine neoplasia types 1-4, PTH = parathyroid hormone, PTHrP = parathyroid-related protein, $1,25(\mathrm{OH})_{2} \mathrm{D}=1$,25-dihydroxyvitamin $\mathrm{D}, 25(\mathrm{OH}) \mathrm{D}=25$-hydroxyvitamin $\mathrm{D}$. Figure adapted from Stokes et al. 2017. ${ }^{2}$

therefore, liver diseases such as viral hepatitis and cirrhosis may increase susceptibility to vitamin A toxicity and worsen liver damage. In 1 study of 41 mostly adult cases of vitamin A hepatotoxicity, some developed cirrhosis with doses as low as $25000 \mathrm{IU} /$ day. ${ }^{8}$ Therefore, it is possible that liver damage from vitamin A toxicity from preformed vitamin A could have affected our patient's ability to appropriately regulate high intakes of provitamin A. Although viral and autoimmune workup for liver disease was negative, we did not do a liver biopsy, so we cannot definitively rule out liver disease from another cause.

Vitamin A is also stored in the kidneys and adrenal glands and excreted partly in urine. Our patient had mild pre-renal acute kidney injury secondary to hypercalcemia, which may have reduced vitamin A clearance and exacerbated toxicity. Other factors that modulate vitamin A potency include low-protein diets, chronic kidney disease and concurrent use of certain vitamins, such as vitamin $D$ and $E,{ }^{7}$ none of which were pertinent in this case. ${ }^{7,9}$ Furthermore, heritable variability in vitamin A metabolism is known, which may explain why toxicity occurs at a wide range of intakes. ${ }^{7,10}$ Interestingly, our patient had a 6 -year-old brother who was consuming a similar diet, yet did not develop symptoms of vitamin A toxicity.

Our case may be of relevance to families shifting to plant-based diets and using vitamin supplements on a regular basis. Short-term dietary studies have shown that as much as $75 \%$ of the general population is ingesting more than the recommended daily allowance of vitamin A, mostly in the preformed form. ${ }^{3}$ Only a fraction of consumers discuss with their physicians their use of dietary supplements such as vitamins. ${ }^{7}$ Our case describes an extreme presentation, but patients may present with milder symptoms of vitamin A toxicity, which may be overlooked or dismissed as vague and nonspecific.

Vitamin A toxicity is an important diagnosis to consider in patients with hypercalcemia. Although our patient had classic findings of vitamin A toxicity, his case had unique features that made the diagnosis challenging, including toxic ingestion with predominantly provitamin A rather than preformed vitamin A, refractory hypercalcemia and bicytopenia despite a normal bone marrow biopsy. Chronic vitamin A toxicity is particularly challenging, as toxicity may occur at what people perceive as a "safe doses" of vitamin A from dietary sources and supplementation. 


\section{References}

1. Bendich A, Langseth L. Safety of vitamin A. Am J Clin Nutr 1989;49:358-71.

2. Stokes VJ, Nielsen MF, Hannan FM, et al. Hypercalcemic disorders in children. $J$ Bone Miner Res 2017;32:2157-70.

3. Penniston $\mathrm{KL}$, Tanumihardjo SA. The acute and chronic toxic effects of vitamin A. Am J Clin Nutr 2006;83:191-201.

4. Allen LH, Haskell M. Estimating the potential for vitamin A toxicity in women and young children. J Nutr 2002;132(Suppl):2907S-19S.

5. Lam HS, Chow CM, Poon WT, et al. Risk of vitamin A toxicity from candy-like chewable vitamin supplements for children. Pediatrics 2006;118:820-4.

6. Vyas AK, White NH. Case of hypercalcemia secondary to hypervitaminosis A in a 6-year-old boy with autism. Case Rep Endocrinol 2011;2011:424712.

7. Hathcock JN, Hattan DG, Jenkins MY, et al. Evaluation of vitamin A toxicity. Am J Clin Nutr 1990;52:183-202.

8. Geubel AP, De Galocsy C, Alves N, et al. Liver damage caused by therapeutic vitamin A administration: estimate of dose-related toxicity in 41 cases. Gastroenterology 1991;100:1701-9.

9. Manickavasagar B, McArdle AJ, Yadav P, et al. Hypervitaminosis A is prevalent in children with CKD and contributes to hypercalcemia. Pediatr Nephrol 2015;30:317-25.

10. Carpenter TO, Pettifor JM, Russell RM, et al. Severe hypervitaminosis A in siblings: Evidence of variable tolerance to retinol intake. J Pediatr 1987;111: 507-12.

\section{Competing interests: None declared.}

This article has been peer reviewed.

The authors have obtained consent from the patient's family.

Affiliations: Divisions of Paediatric Medicine (Lorenzo, Gill) and Endocrinology (Harrington), Department of Paediatrics, The Hospital for Sick Children and University of Toronto; Division of Clinical Pharmacology and Toxicology (Nadeau), Department of Medicine, University of Toronto, Toronto, Ont.

Contributors: All of the authors contributed to the conception and design of the work, drafted the manuscript, revised it critically for important intellectual content, gave final approval of the version to be published and agreed to be accountable for all aspects of the work.

Acknowledgements: The authors thank the patient and his family for allowing them to publish this case report. The authors also thank Dr. Shinya Ito for reviewing the manuscript and providing toxicology expertise, and Jordan Beaulieu for providing input on the dietary review.

Disclaimer: Peter Gill was a member of the Editorial Advisory Board for CMAJ and was not involved in the editorial decision-making process for this article.

Correspondence to: Peter Gill, peter.gill@sickkids.ca 